Revista de Comunicación y Salud, 2020, Vol. 10, no 3, pp. 73-85

Editado por Cátedra de Comunicación y Salud

ISSN: 2173-1675

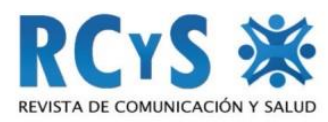

Enviado 20 de mayo de 2020

Aprobado 14 de agosto de 2020

\title{
LA DISCRIMINACIÓN POR COLOR DE LA PIEL EN EL DEBATE EDUCATIVO ACTUAL: ¿ANTROPOLOGÍA FRENTE A EDUCACIÓN?
}

\author{
The discrimination by skin color in the current educational debate: \\ Anthropology versus Education? \\ Luisa Martínez O'Farrill'1 \\ Universidad de Ciencias Pedagógicas "Enrique José Varona". Cuba \\ manuelamo@ucpejv.edu.cu
}

\section{Resumen}

El tema de las discriminaciones sociales por color de piel, sexo, religiones o estereotipos sobre los géneros, bien podría parecernos aspectos superados dentro del contexto de la Sociedad Cubana actual. Sin embargo, la supervivencia de este flagelo de la discriminación acompaña el desarrollo de nuestra sociedad en el presente, alimentando en algunas personas la toma de decisiones con respecto a individuos con los cuales entran en contacto bajo determinadas condiciones laborales, de estudio, relaciones interpersonales y de pareja. El objetivo 57, aprobado en la Primera Conferencia Nacional del Partido en Cuba, celebrada en enero del pasado (2011), habla de enfrentar los prejuicios y conductas discriminatorias por color de piel, género, creencias religiosas, orientación sexual, origen territorial y otros que son contrarios a la Constitución y las leyes, atentan contra la unidad nacional y limitan el ejercicio de los derechos de las personas. La Universidad ante el llamado del país, tiene una alta responsabilidad en la lucha por la superación de estas mentalidades que son rezagos del pasado. Pero sobre todo alejadas del ideal humanista tradicional de la Sociedad Cubana, a cuya conquista dedicaron sus vidas los mejores hijos, en toda la trayectoria temporal de nuestra historia y cultura.

Palabras clave: Raza; Racismo; Discriminación social; Discriminación racial en Cuba; Sociedad cubana, Universidad

\begin{abstract}
The theme of the social discriminations for color of skin, sex, religions or stereotypes on the textiles, very well I could look like aspects surpassed within the context of the presentday Society Cubana. However, the survival of this whip of discrimination accompanies the development of our society in the present, feeding in some people the decision making
\end{abstract}

${ }^{1}$ Autora para correspondencia: Luisa Martínez O’Farrill. Universidad de Ciencias Pedagógicas “Enrique José Varona". La Habana, Cuba. manuelamo@ucpejv.edu.cu 
La discriminación por color de la piel en el debate educativo actual: ¿Antropología frente a Educación?

regarding individuals with the ones that they enter with in contact under determined working conditions, of study, personal relations and of couple. The objective 57, pass mark in the First National Lecture of the Party of Cuba, celebrated in January of the past (2011), talk about confronting prejudices and discriminatory conducts for color of skin, kind, religious beliefs, sexual orientation, territorial origin and other ones that they are contrary to the constitution and laws, they threaten the national unit and they limit the exercise of the rights of the people. The University before the call of the country, deems a high responsibility the overcoming of these intentions that are aftereffects of the past in the fight as. But most of all far away of the humanistic traditional ideal of the Cuban society, to whose conquest the children dedicated their better lives, in the whole temporary trajectory of our history and culture.

Keywords: Race; Racism; Social discrimination; racial discrimination in Cuba; Cuban society; University

Cómo citar el artículo

Martínez O'Farrill, L. (2020). La discriminación por color de la piel en el debate educativo actual: ¿antropología frente a educación? Revista de Comunicación y Salud, 10(3), 5365. doi: https://doi.org/10.35669/rcys.2020.10(3).73-85

"La Naturaleza no hace razas, sino individuos humanos. La raza es hechura social." Ortiz, p. 380:2, El engaño de las razas, 1946

\section{INTRODUCCIÓN}

Los años 2000 han sido pródigos en sus avances y persistencia por sacar a la luz con fuerzas renovadas el tema de la discriminación en cualquiera de sus formas; pero de manera especial en el aspecto racial, como muchos todavía denominan al referirse a este aspecto doloroso de la discriminación y desigualdad social por el color de la piel.

Los ropajes bajo los que se presentan son diferentes en atención al escenario social que les sirve de fondo, ya sean la xenofobia, los desplazamientos forzosos de etnias como los palestinos, gitanos, mexicanos y otros, considerados despectivamente minorías, olvidando conscientemente que se trata de seres humanos.

Ha sido reconocido por el Dr. Esteban Morales, en entrevista del periódico Trabajadores, publicada el 14 de diciembre de 2009, lo que cito: " Sería absurdo pensar que en Cuba no existen problemas raciales, estereotipos negativos, discriminación y racismo, como lastres, aunque no solo como eso, sino como algo que la sociedad es capaz de reproducir en su imperfección.

La necesidad de revisar los programas de estudios e insertar el tratamiento del tema de la discriminación por color de piel tiene prioridad en el presente, de su sistematización en la formación de las generaciones actuales y próximas dependerá la eliminación 
La discriminación por color de la piel en el debate educativo actual: ¿Antropología frente a Educación?

gradual en la conciencia de la sociedad de este flagelo, así como, de los estereotipos culturales que favorecen la supervivencia del racismo en cualquiera de sus formas.

Reconoce en el trabajo periodístico las diferencias de enfoques sobre el tema en el país y las interpretaciones que se han producido alrededor de Cuba desde el exterior, al establecerse una analogía entre la situación de los afroamericanos con los " afrocubanos .

Esta situación tuvo como contexto, la declaración de algunos afroamericanos en apoyo a la lucha por derechos civiles en Cuba. Situación bien alejada del marco social reinante en el país, bajo la Revolución triunfante desde 1959, la que de forma sistemática y permanente ha combatido las manifestaciones de discriminación " racial " en espíritu y por medio de las expresiones que sobre el tema han pronunciado los dirigentes de la más alta dirección del país.

El propio término " afrocubano ", no resiste el análisis, no soporta, en nosotros, un estudio de diferenciación étnica o de composición social, en virtud del mestizaje que de forma paulatina ha ejercitado la población cubana hasta el presente, con lo que ha ido eliminando cada vez más, los arquetipos tradicionales de colores de pieles: negro, blanco, amarillo y mestizo, con el incremento de este último de forma considerable, pero que no afecta, la supervivencia en la subjetividad individual de los arquetipos diferenciadores y las pretensiones de aplicarlos en las relaciones sociales de las que participan, bien sean desde las religiones, el folclor social, la música, la danza, las tradiciones u otras expresiones populares culturales.

Múltiples son los congresos internacionales y nacionales donde el tema sirve de inspiración a numerosos estudiosos, investigadores, profesores, personal de la salud, los que aportan testimonios sobre la pervivencia de este fenómeno a escala regional e internacional, por ejemplo el Encuentro Iberoamericano del Año Internacional de los Afrodescendientes: Afro XXI, en Salvador de Bahía, 2011, reconoció y cito: " La juventud afrodescendiente es uno de los grupos más afectados por procesos estructurales de exclusión, inequidad y pobreza "(fin de la cita); pero en particular nos asombra la presencia que todavía tiene en Cuba.

El llamado de la Asamblea Nacional, publicado por el Periódico Granma, 21 de diciembre del 2011, en el cual el co. Ricardo Alarcón, miembro del Buró Político PCC expresara durante la Intervención, ante la Comisión de Educación, Cultura, Ciencia y Tecnología, así lo constata: " es necesario combatir cualquier acción de discriminación, violatoria de las leyes cubanas, como un principio intrínseco de la Revolución que promueve esencialmente la unidad y la solidaridad.

Más adelante señalaba: " (...) es una urgencia asumir la Historia como esencia para destruir esos flagelos que persisten hasta nuestros días. " Finalmente puntualizaba: " El fenómeno esencialmente cultural, es incompatible con el Socialismo, (...) es un mal latente ante el cual es imposible cerrar los ojos. " 
La discriminación por color de la piel en el debate educativo actual: ¿Antropología frente a Educación?

El llamado del VI Congreso del PCC ${ }^{2}$, de la Conferencia Nacional, así como el llamado de la prensa en que de forma esporádica se ha tratado el tema, sin afectar la profundidad científica de los análisis, en los que se insiste de forma constante en el papel de la educación como vehículo esencial para la transformación de la mentalidad de las jóvenes generaciones y enfrentar la lucha social por una sociedad mejor, más justa en la igualdad de los grupos que alberga en su interior.

Las oportunidades para el desarrollo individual y colectivo tiene continuidad en el trabajo que desarrolla el Partido en la aplicación y desarrollo de los acuerdos de la magna reunión, al respecto cito el Dictamen de la Comisión No. 2: Trabajo Político e Ideológico, que bajo el formato de resumen de la Conferencia del PCC, publicara el Periódico Granma, 1 de febrero del 2012:

. (...). Indispensable para garantizar la unidad de todos los patriotas y el ejercicio de los derechos de las personas es enfrentar todo prejuicio y conducta discriminatoria, en correspondencia con el deseo martiano declarado en la Constitución de la República acerca del culto de los cubanos a la dignidad plena del hombre. (...)

El reconocimiento más evidente a la presencia de la discriminación puede palparse en parte del texto resumen de las sesiones de trabajo de la Comisión No. 3 sobre la Política de Cuadros, cuando establece:

" (...) incrementar de manera progresiva y sostenida, la promoción de mujeres, negros, mestizos y jóvenes a cargos de dirección, cuestión en la que a pesar de los reiterados señalamientos realizados por la máxima dirección del país, todavía no se trabaja con suficiente intencionalidad, por lo que no se alcanzan los propósitos trazados. (...) "Periódico Granma, 2 de febrero del 2012.

El presente nos convoca a retomar el pasado cercano, específicamente la primera mitad del siglo XX. En este período en el que Cuba tomó la posición de vanguardia en el combate contra las discriminaciones raciales en el país, la región latinoamericana y a nivel internacional. Contaba con un antecedente inmediato en el pensamiento de José Martí, que llegó a formular una tesis definitoria de su acción para el futuro de Cuba que cito: " No hay odios de razas, porque no hay razas.

Resulta indispensable esclarecer que para la elaboración del presente artículo fue empleada como metodología el análisis documental, en este orden la triangulación teórica favoreció el esclarecimiento de las relaciones cultura - raza, sociedad - raza, así como las expresiones que ha tenido en diferentes momentos históricos. Al mismo tiempo, reafirmar la trascendencia social que puede alcanzar una educación en el respeto a la diversidad por color de piel.

${ }^{2}$ Partido Comunista de Cuba

Revista de Comunicación y Salud, 2020, Vol. 10, no 3, pp. 73-85 
La discriminación por color de la piel en el debate educativo actual: ¿Antropología frente a Educación?

\section{Etimología de la palabra: Raza}

La búsqueda del significado etimológico de la palabra como parte de la construcción de la gama de significados en su contenido, que permitieran un análisis más objetivo sobre el tema y su antigüedad, ha seguido el siguiente derrotero:

El Diccionario de la Lengua Española ARISTOS. Raza: casta o calidad de linaje.// Cada uno de los grupos en que se subdividen algunas especies botánicas y zoológicas, cuyos caracteres diferenciales se perpetúan por herencia.

En The Pocket Oxford Dicctionary. Race2: sustantivo: casta, linaje, estirpe, raza. Por su parte el Diccionario Francés - Español, conocido por Manual Amador, MINED, 1978, entiende por Race: raza. Racehumaine.

El Diccionario Portugués - Español. Raza: raça, estirpe, casta. Diccionario Avallardi, Italiano - Español, 1995, comprende el vocablo Raza: razza. Sustantivo femenino.

A modo de resumen valorativo podemos expresar que: Raza: es un concepto que alude a la mayor división humana, atendiendo a las características físicas. // División en razas, en género, especies, castas, grupos de personas. // División de criaturas vivas. Examinando el concepto desde las posiciones más actuales reconocidas por el Diccionario de Filosofía, Herder, 2004.

Algunos autores como Fernando Ortiz Fernández, en El engaño de la razas, 1946 y Armando Entralgo en Problemas del estudio de la Historia de África, páginas $15-28$. Revista Etnología y Folklore, No. 7, 1969, coinciden en señalar que:

o El concepto raza tiene un origen desconocido y etimología poco clara.

o Existe coincidencia al reconocer que el concepto se emplea en el período mercantil hacia Asia y América, con anterioridad no hay pruebas de su uso.

o Se considera que el vocablo surge en Europa Renacentista, aunque su empleo no se ha encontrado en las narraciones de viajeros e historiadores. Se habla de existencia de pueblos diferentes en cultura, comportamiento, costumbres.

o Unos plantean origen en la palabra italiana: razza, otros la ubican en la palabra árabe ras: grupo de descendientes.

La autora de este trabajo e investigadora del tema por más de quince años, no ha encontrado este último significado en lengua árabe para ras, sino punta de tierra, jefe, pronombre, según Diccionarios de Lengua Francesa consultados, como el ya referido, por ello estima puede ser una declinación por uso lingüístico, para indicar pertenencia a lugar.

Del mismo modo ha examinado las teorías antropológicas sobre raza y al respecto comparte el resultado:

\subsection{Teoría de la medición de ciertos caracteres corporales o de los tipos humanos.}

Como principal característica presenta una teoría descriptiva sobre bases morfológicas no biológicas, es decir la forma craneal, estatura, pigmentación, cabello, cara, nariz. Ejemplos de ella son: 
La discriminación por color de la piel en el debate educativo actual: ¿Antropología frente a Educación?

o $1^{\text {a }}$ clasificación de razas. Criterio: Color de piel. (A. Blumenbach, $1752-1840$ ): 5 razas -5 continentes: 1) caucásica, blanca o europida, 2) mongólica, amarilla y 3) etíope o negra. 4) Americana o cobriza, 5) malaya o morena.

o 1950. Boyd, clasifica incluyendo como factor de diferenciación humana el grupo sanguíneo.

o Coon, Birdsell y Gran, clasifican 34 razas, atendiendo a factores genéticos.

En esencia son evasiones conceptuales racistas que buscan la raza biológica. $A$ propósito estudios actuales llevados a cabo en la Universidad de Vermont, Estados Unidos, producen investigaciones bajo la teoría de Boyd, de 1950 y han confirmado la existencia de dos nuevos grupos sanguíneos, $L$ y J, al mismo tiempo se ha reconocido que estos grupos son más frecuentes de lo que se imaginaba y estiman son muy frecuentes en Asia.

Esta situación ha desencadenado intereses y preocupaciones, de un lado, la ampliación del conocimiento de la composición sanguínea de los seres humanos en mayor amplitud impacta positivamente en el conocimiento sobre las incompatibilidades y elimina en consecuencia la ocurrencia del número de muertes por esta causa. Pero por otro lado, este conocimiento ha conformado una caracterización de las personalidades, atendiendo al grupo sanguíneo, de tal modo los individuos del grupo A, según los japoneses, se caracterizan por ser perfeccionistas; pero demasiado ansiosos.

Los del grupo $B$, son alegres excéntricos y egoístas. Los $A B$ se describen como creativos, misteriosos e impredecibles. Por su parte los pertenecientes al grupo $O$ se describen como curiosos, generosos y testarudos.

El lado negativo de este conocimiento ha llegado a ser incluido el conocimiento del grupo sanguíneo para el otorgamiento de vacantes laborales, a la separación de los niños desde el jardín infantil, bajo el pretexto de la personalidad, entre otros efectos que están por manifestarse y estudiarse en el futuro próximo.

\subsection{Teoría de la jerarquía racial humana (Cuadrumanos).}

Principal característica: es una teoría descriptiva sobre bases morfológicas de pigmentación, cabello, cara, nariz, como fundamento de una gradación evolutiva: del mono al negro, al amarillo y al blanco: M. N. A. B.

o Base 1: por la abertura del ángulo facial, en escala de menor a mayor: M. N. B. A.

o Base 2. por la relativa evolutividad del cabello: M. N. B. A.

o Base 3. por la estructura del pelo: M. A. B. N.

o Base 4: por la relativa abundancia de pelo: B. A. N.

\subsection{Teoría de la relación capacidad craneal (tamaño) - inteligencia (2da mitad siglo XIX).}

Tiene como principal característica ser una teoría descriptiva que descansa sobre bases antropométricas y morfológicas del cerebro, examinadas de conjunto como 
La discriminación por color de la piel en el debate educativo actual: ¿Antropología frente a Educación?

medidas - valores determinantes de la capacidad de inteligencia en grandes hombres. Tuvo como principales representantes a: R. Wagner, P. Broca, Donaldson y otros.

La Antropología Física fue el escenario principal para el desarrollo de la Teoría del tamaño cerebral, en síntesis, establecía una analogía: Grandes hombres - grandes cerebros.

R. Wagner destruye el mito y solicitó a geniales hombres de Europa que donaran sus cadáveres para tales estudios, respondieron a la solicitud grandes hombres como Beethoven, La Fontaine, Kant, etc., sin embargo, los estudios practicados no corroboraron siempre la teoría.

Bronislaw Malinowski, al calor de los estudios sobre los que se revelaron informaciones concluyó: " No se puede probar que un hombre tenga un alma menor por el hecho de que aquél tenga un cráneo más pequeño. No se puede medir un alma. "

En Cuba los ecos de tales investigaciones condujeron por 1899, a tres médicos cubanos estudiaron exhaustivamente el cráneo de Antonio Maceo. Los médicos fueron: J. L. Montalvo, Carlos de la Torre y de la Huerta, y Luis Montané Dardé.

Los tres galenos, iniciadores de la Antropología en Cuba, demostraron que a José Martí le asistía toda la razón cuando consideró que el Titán de Bronce tenía tanta fuerza en el brazo como en la mente. Tomaron en cuenta para ello, el estudio sobre la bases de las medidas de P. Broca

El estudio de su función pensante reveló:

o Dividido el cráneo de Maceo en dos semicircunferencias, se comprobó un desarrollo impresionante de la parte anterior en relación con la posterior.

o Otro hallazgo importante fue la comprobación de que sus suturas craneales permanecían insólitamente abiertas, no obstante su edad, en franco crecimiento favorable desde el punto de vista intelectual.

Tomaron en cuenta que, a su muerte, el General Antonio Maceo y Grajales contaba 51 años, sin embargo, su cerebro reflejaba una persona de unos 48 años.

Las conclusiones del estudio practicado revelaron por el análisis antropométrico realizado (medición de los huesos) que Maceo, mestizo, muy cercano a los dos metros de estatura, tenía en porción craneal occipital una anomalía de carácter óseo denominada epactal, incal o hueso del Inca, presente solo en cráneos de personas excepcionales.

Martí, en una misiva dirigida al General Antonio, el 20 de febrero de 1894 (página 53, tomo IV del Epistolario de Luis García Pascual) le expresaba: " Usted es para mí, y lo digo a boca llena y a pluma continua, uno de los hombres más enteros y pujantes, más lúcidos y útiles a Cuba...". 
La discriminación por color de la piel en el debate educativo actual: ¿Antropología frente a Educación?

Trazó un magnífico retrato del Lugarteniente General del Ejército Libertador de Cuba: "Firme es su pensamiento y armonioso como las líneas de su cráneo ". Estas aseveraciones de José Martí ponen al descubierto el respeto no solo del militar, sino del hombre excepcional que fuera el Titán de Bronce.

Indiscutible resulta que el estudio antropológico del cadáver de Antonio Maceo resultó intencionado y en este sentido aleccionador, de una parte fue una oportunidad científica de proporcionar elementos veraces para las insinuaciones racistas sobre su capacidad, inteligencia y la discriminación de que fuera objeto a lo largo de las dos guerras, situación que le persiguiera hasta después de su muerte. Por otro lado, puede estimarse este acto como un desmentido rotundo sobre su incapacidad y el hecho de ser solamente un diestro y valiente militar mambí, al superar ampliamente las medidas craneales y cerebrales requeridas.

En una carta, poco difundida en el presente, Maceo nos daba pruebas una vez más de su talla moral e integridad personal, su cubanía por encima de cualquier duda 0 emociones humanas dudosas, la simple lectura del texto es elocuente, por ello se introduce de forma íntegra:

"Una queja de Antonio Maceo

Antonio Maceo y Grajales, natural de la Ciudad de Cuba, Brigadier del E. L. y en la actualidad Jefe de la $2^{\text {a }}$ División 1r. Cuerpo, ante Ud. Usando la forma más respetuosa se presenta y expone: Que de mucho tiempo atrás, si se quiere, he venido tolerando, especies y conversaciones que verdaderamente condenaba al desprecio porque las creía procedentes del enemigo; que conozco, que esgrime y ha usado toda clase de armas para desunirnos y ver si así puede vencernos; pero más tarde, viendo que la cuestión clase tomaba creces y la dan otra forma; trató de escudriñar de donde procedía y convencido al fin no proceden del enemigo; sino doloroso es decirlo, de individuos hermanos nuestros, que olvidándose de los principios republicanos, que observar debían, se ocupan más bien en servir miras políticas particulares; por lo tanto en razón de lo dicho, se cree obligado a acudir al Gobierno que Ud. representa, para que bien penetrado de las razones, que más adelante expondrá; proceda como fuese justicia; y volviendo, dicte las medidas necesarias, a fin de que en ningún tiempo se tache ni parezca dudosa la conducta del exponente, ni su honor con la más ligera mancha; pues a los deseos de toda su vida han sido, son y serán servir a su país, defendiendo los principios proclamados, y exponer su vida, como tantas veces lo ha hecho, porque la causa triunfe y se mantengan incólumes los Sacro-Santos principio de libertad y de independencia.

El exponente, Co. Presidente, supo hace algún tiempo por persona de buena reputación y prestigio, que existía un pequeño círculo, que propalaba haber manifiesto al Gobierno " no querer servir por serles contrario y poner mirasen sobreponer los hombres de color a los hombres blancos ". Tal es la cuestión que ese círculo agita: y es de creer la han lanzado para herir en lo más vivo al exponente; porque con ella quieren servir intereses políticos particulares, y por de contado, para ver si así

Revista de Comunicación y Salud, 2020, Vol. 10, no 3, pp. 73-85 
La discriminación por color de la piel en el debate educativo actual: ¿Antropología frente a Educación?

inutilizaban al que consideran un estorbo para sus planes; tratando de hundir, ya que de otro modo no pueden al hombre que ingresó en la revolución sin otras miras que las de dar su sangre por ver si su Patria consigue verse libre y sin esclavos.

Y como el exponente precisamente pertenece a la clase de color, sin que por ello se considere valer menos que los otros hombres; no puede ni debe consentir, que lo que no es, ni quiere que suceda, tome cuerpo y siga extendiéndose, porque así lo exigen su dignidad, su honor militar, el puesto que ocupa y los lauros que tan legítimamente tiene adquiridos. $Y$ protesta enérgicamente con todas sus fuerzas para que ni ahora ni en ningún tiempo se le considere partidario de ese sistema, ni menos se le tenga como autor de doctrinas tan funestas; máximo cuando forma parte y no despreciable de esta República democrática, que ha sentado como base principal la libertad, la igualdad y la fraternidad y que no reconoce jerarquías. (...)

Campamento en Barigua a 16 de mayo de $18769^{\circ}$ de la Independencia P. y L. Antonio Maceo. " (1)

Tomada la copia del archivo de la Sociedad Económica de Amigos del País, La Habana

\section{Algunos eventos importantes que tuvieron este tema como centro en el pasado siglo XX.}

1938, E. Unidos. La Reunión de la Asociación Antropológica Americana. En ella se tomó el acuerdo: Repudio al racialismo y del uso de la Antropología para argumentaciones racistas.

1940, Washington. 8o Congreso Científico Panamericano. Acuerdo. "Que la Antropología rehúsa prestar apoyo científico alguno a la discriminación contra cualquier grupo social, lingüístico, religioso o político, bajo el pretexto de ser un grupo racialmente inferior. " (propuesta formulada por F. Ortiz)

1943, México. 1er Congreso Demográfico Interamericano. Ac. Que el vocablo razas aplicado en sentido impropio a seres humanos fuese prohibido en documentos oficiales (legislativos, judiciales y administrativos) de los Gobiernos. (Propuesta de F. Ortiz)

Otro acuerdo fue: La fundación del Instituto Internacional de Estudios Afroamericanos, con sede en México.

El acta de fundación fue firmada por los cubanos Miguel Covarrubias, Julio Le Riverend y Fernando Ortiz. Como resultado de las elecciones para la Revista Científica: Afroamérica, la composición quedó de la siguiente forma:

- Comité Ejecutivo: Director: Dr. F. Ortiz

- Consultores: Prof. Miguel Covarrubias y Dr. Julio Le Riverend. 
La discriminación por color de la piel en el debate educativo actual: ¿Antropología frente a Educación?

1945, Castillo de Chapultepec, México. Fue celebrado el 1er Congreso Interamericano de Demografía, durante el mismo fueron aprobadas las Resoluciones: XLI contra la discriminación racial, XLIII sobre la Difusión y XXIX. Sobre revisión de textos escolares.

El resultado de este proceso de trabajo en diferentes congresos y espacios académicos dejó demostrada la activa participación de Cuba, representada por algunos de sus intelectuales de vanguardia, tales son los casos de Fernando Ortiz, Julio Le Riverend y Miguel Covarrubias. Interesante resulta comprobar que los acuerdos y resoluciones sostienen su vigencia y que versan acerca de las propuestas que se plantean hoy para el mejoramiento social, por ello debemos estimarlas como una continuidad del pensamiento cubano más revolucionario y progresista.

La reeducación debe comprender el enfoque de la educación como el escenario profesional que tiene delante la tarea suprema de la humanización del hombre, la apropiación de valores, tradiciones, costumbres, que en última instancia se producen por la aprehensión de la cultura nacional e internacional.

Finalmente reconocer que el avance científico - tecnológico de las últimas décadas del siglo XX, ha aportado a los renovados estudios sobre el tema:

1. La clasificación racial de la especie humana ha dejado de tener sentido riguroso científico. Considera más importante las diferencias genéticas que el color de piel, cabellos, labios u ojos.

2. Han demostrado que los caracteres sanguíneos o el tamaño de los dientes, tienen distribuciones planetarias diferentes y en este sentido, no son mediciones suficientes para fundamentar la racialidad.

Por su parte, el notable biólogo Luigi Cavalli-Sforza, declaró en reunión de la Asociación Americana para el Avance de la Ciencia (AAAS), celebrado en la ciudad de Atlanta, 1995 (febrero) que: " Raza es un concepto bastante inútil, porque no se puede agrupar a los humanos, ya que las diferencias genéticas entre " razas", excepto en casos de aislamiento geográfico continuado, son muy pocas. "Existe confusión en las nociones: raza y etnia.

Raza es una noción biológica. Etnia es una noción cultural. Es la noción más adecuada para tratar las diferencias humanas. Hay más culturas que razas. Una misma etnia contiene diversidad de culturas en su seno.

Como concepto de clasificación y ordenamiento biológico: variedad, especie, subespecie y género. Es o pretende ser un agrupamiento de los seres humanos por sus caracteres morfológicos, fisiológicos y psíquicos, fijos y transmisibles hereditariamente. Implica una metodología de clasificación inferior a especie y género, análogo a subespecie. Ortiz. El engaño de las razas, pág. 370. 
La discriminación por color de la piel en el debate educativo actual: ¿Antropología frente a Educación?

Como concepto político: Raza se confunde con una nucleación histórica, ora con el pueblo o la nación en cuanto a lo exterior, ora con la clase social o la casta en lo interior. (Nación, pueblo, gente, casta, clase).Ortiz. El engaño de las razas, pág. 61.

Como concepto cultural: Raza se trastrueca por forzada sinonimia con el concepto cultura, aplicado como distintivo de una determinada agrupación humana, en cuanto a su capacitación, organización y conductas sociales. Ortiz. El engaño de las razas, pág. 61

Como concepto científico: raza representa "una gran división de la humanidad cuyos miembros, aun cuando individualmente variados, se caracterizan como grupo humano, por una cierta combinación de rasgos morfológicos principalmente no adaptativos, los cuales proceden de una común descendencia. Asevera Hooton, Ernest, en El mito de la raza a la luz de la Antropología. La Nueva Democracia, N. Y., septiembre de 1936.

Cuba como parte del desarrollo de la Genética Médica ha llevado a cabo estudios recientes, 2011 - 2012, acerca de la composición de la población cubana, tomando como base los genes ancestrales, el estudio para sorpresa de todos ha demostrado que tenemos una composición genética mestiza, somos en un $72 \%$ portadores de genes europeos, $8 \%$ amerindios y en un $20 \%$ negros. Lo que nada tiene que ver con el color de la piel, cabellos y ojos.

Atendiendo a los genes ancestrales un individuo de color de piel negra puede tener mayores genes europeos o amerindios que negros y viceversa un individuo blanco de piel puede ser un portador genético de genes ancestrales negros en mayor cantidad que europeos, a pesar del aspecto físico externo.

Estas conclusiones desarrolladas por la Genética Médica demuestran la validez de las afirmaciones martianas, cuando en Nuestra América, trabajo publicado en El Partido Liberal, México, el 30 de enero de 1891, escribió: " No hay odio de razas, porque no hay razas. (...) El alma emana igual y eterna, de los cuerpos diversos en forma y color. " (Fin de la cita, Obras Completas. Tomo 6, página 22)

\section{CONCLUSIONES}

1. Toda herencia humana es un fenómeno binario $\left(A+B=A^{\prime} B^{\prime}\right)$

2. Herencia: es una palabra con sentido biológico y social. Entonces y como consecuencia: A'B' es biológicamente y por herencia único. "La herencia individual es en realidad científica. " Franz Boas.

3. En la sociedad el hombre recibe múltiples influencias culturales que lo definen. Natura y hechura al decir de Fernando Ortiz, en la participación social diría Carlos Marx. Y en este proceso la educación es parte vital.

4. La concepción de la diferenciación social a partir de las razas ha sido un engaño sociopolítico desmentido en el propio desarrollo de las investigaciones científicas del pasado siglo XX y posmodernas.

\section{BIBLIOGRAFÍA}

Revista de Comunicación y Salud, 2020, Vol. 10, nº 3, pp. 73-85 
La discriminación por color de la piel en el debate educativo actual: ¿Antropología frente a Educación?

Diccionario de Filosofía, enciclopedia digital Herder. (2004). Recuperado de https://encyclopaedia.herdereditorial.com/

Dictamen de la Comisión No. 2: Trabajo Político e Ideológico. (2012, febrero 1). Granma. [Publicado bajo el formato de resumen de la Conferencia del PCC]. Recuperado de http://www.granma.cu/granmad/secciones/1ra-conferencia-pcc/dictamen2.html

Resumen del Dictamen de la Comisión No. 3. Política de Cuadros. (2012, febrero 2) Granma. [Publicado bajo el formato de resumen de la Conferencia del PCC]. Recuperado de http://www.granma.cu/granmad/secciones/1ra-conferenciapcc/dictamen3.html

Detrás de la ciencia. (2012, marzo 9) Juventud Rebelde. Recuperado de http://www.juventudrebelde.cu/

Martínez O'Farrill, L. (2017). La historiografía en el análisis del negro en Cuba. Tlatemoani: revista académica de investigación, 8(24), 159-190. Recuperado de https://dialnet.unirioja.es/servlet/articulo?codigo=7283805

Martínez O'Farrill, L. (2018). Yo soy el otro en la historia social cubana: Historia social del negro en Cuba. Unión Europea: Editorial Academia Española - SIA OmniScriptumPublishing.

Ortiz, F. (1975). El engaño de las razas. La Habana, Cuba: Editorial Ciencias Sociales.

PCC (Eds.). (2011). Lineamientos Económicos, Políticos y Sociales de la Sociedad Cubana actual. La Habana, Cuba: Editorial Consejo de Estado.

Revista Bimestre Cubana No. 1, copia en Archivo de la Sociedad Económica de Amigos del País, de la Habana.

Revista Etnología y Folklore, No. 7, 1969

Trabajadores, periódico. Entrevista al Dr. Esteban Morales, publicada el 14 de diciembre de 2009.

Morales, E. (7 de enero de 2009). Comprender la problemática racial cubana. Recuperado de http://estebanmoralesdominguez.blogspot.com/2009/01/comprenderla-problematica-racial.html

UNESCO. Informe. Asociación Americana para el Avance de la Ciencia (AAAS), Atlanta, Estados Unidos, febrero de 1995.

\section{AUTORA}

\section{Luisa Martínez O’Farrill}

Revista de Comunicación y Salud, 2020, Vol. 10, nº 3, pp. 73-85 
La discriminación por color de la piel en el debate educativo actual: ¿Antropología frente a Educación?

Universidad de Ciencias Pedagógicas "Enrique José Varona". Cuba

manuelamo@ucpejv.edu.cu

\section{Notas}

(1) Los subrayados en el texto de la carta resaltan los aspectos fundamentales con sentido discriminatorio por cuestión de color de piel, denunciados por el Lugarteniente general del Ejército Libertador, Antonio Maceo y Grajales. El documento o carta ha sido reproducida de forma íntegra, es copia fiel del original que aparece en Revista Bimestre Cubana, No. 1, publicada a comienzos del siglo $X X$.

(2) El papel de la reeducación en la superación del asunto de la racialidad será objeto de una segunda parte del presente trabajo, tal como nos fuera recomendado. 